\title{
ANÁLISE BIBLIOMÉTRICA DOS ESTUDOS NACIONAIS EM CLÍNICA PSICODINÂMICA DO TRABALHO
}

\author{
Bibliometric Analysis of the National Studies in Psychodynamic Work Practice \\ Análisis Bibliométrico de los Estudios Nacionales en clínica Psico-dinámica del Trabajo \\ L'analyse Bibliométrique des Études Nationales à la Psychodynamique du Travail Clinique
}

Lúcio de Souza Machado

Doutorando em Psicologia, Pontifícia Universidade Católica de Goiás (PUC-GO).

Kátia Barbosa Macêdo

Professora Titular, Doutorado em Psicologia, Pontifícia Universidade Católica de Goiás (PUC-GO).

Recebido em: 06/08/2015 / Revisado em: 10/11/2015 / Aceito em: 17/03/2016

\begin{abstract}
Resumo
Esta pesquisa objetivou explorar o panorama dos artigos sobre psicodinâmica do trabalho(PDT) publicados no Portal de Periódicos CAPES/ MEC, em língua portuguesa, no período de 2000 a 2014. A pesquisa classifica-se como descritiva e bibliométrica. Para o levantamento dos artigos, empregaram-se palavras-chaves extraídas da teoria da clínica psicodinâmica do trabalho. Foram localizados 95 artigos no período, o que corresponde a uma média de 6,33 artigos por ano. Os resultados indicaram que a maior parte das publicações concentrou-se nos anos de 2009 a 2012. Os artigos podem ser considerados como de boa qualidade, pois foram publicados, em sua maioria, em periódicos com Qualis/CAPES superior a B3. Dentre as principais temáticas, observou-se que os autores priorizam o estudo e análise do trabalho, e a sua relação com a saúde e sofrimento do trabalhador. Quanto ao perfil dos autores, verificou-se que, em sua maioria, são do gênero feminino e com doutorado. Em relação à formação de redes de pesquisa, identificaram-se quatro grandes redes entre os autores, em que se destacam as regiões Sudeste, Sul e Centro-Oeste e Nordeste como mais representativas. Conclui-se que a pesquisa em PDT pode ser considerada modesta, porém de boa qualidade, em que se preza a cooperação científica.
\end{abstract}

Palavras-chave: saúde mental; psicodinâmica do trabalho; Portal de Periódicos Capes/MEC; pesquisa bibliométrica.

Abstract

This research aimed to explore the panorama of the articles on Work Psychodynamics (PDT), published in the Portal of Journals CAPES I MEC, in Portuguese language, from 2000 to 2014. The research is classified as descriptive and bibliometric. For the survey of the articles key words extracted from the theory of clinical Psychodynamics of Work were used. There were 95 articles in the period, which corresponds to an average of 6.33 articles per year. The results indicated that most of the publications focused on the years 2009 to 2012. The articles can be considered as good quality, since they have been published for the most part in journals with Qualis / CAPES higher than B3. Among the main themes, it was observed that the authors prioritize the study and analysis of the work, and its relation with the health and suffering of the worker. As for the profile of the authors, it was verified that most of them are female and with doctor degree. In relation to the formation of research networks, we identified four major networks among authors, in which the south-east, south and center-west regions stand out as the most representative. It is concluded that the research in PDT can be considered modest, but of good quality, in which scientific cooperation is valued.

Keywords: mental health; work psychodynamics; Portal of Journals CAPES / MEC; bibliometric research 


\section{Resumen}

Esta investigación objetivó explorar el panorama de los artículos sobre Psico-dinámica del Trabajo (PDT), publicados en el Portal de Periódicos CAPES/MEC, en lengua portuguesa, en el periodo de 2000 a 2014. La investigación es descriptiva y bibliométrica. Para la recogida de los artículos utilizamos palabras-clave extraídas de la teoría de la clínica Psico-dinámica del Trabajo. Fueron localizados 95 artículos en el periodo, correspondiendo a una media de 6,33 artículos por año. Los resultados revelaron que la mayor parte de las publicaciones se concentró en los años de 2009 a 2012. Los artículos pueden ser considerados de buena calidad porque fueron publicados, en su mayoría, en periódicos con Qualis/CAPES superior a B3. Entre las principales temáticas, se observó que los autores dan prioridad al estudio y análisis del trabajo y su relación con la salud y sufrimiento del trabajador. Con relación al perfil de los autores fue verificado que en la mayoría son del género femenino y con doctorado. En relación a la formación de red de investigación, se identificaron cuatro grandes redes entre autores, en que se destacan las regiones sudeste, sur y centro-oeste como más representativas. Em relação à formação de redes de pesquisa, identificaram-se quatro grandes redes entre autores, em que se destacam as regiões sudeste, sul e centro-oeste como mais representativas. Se concluye que la investigación en PDT puede ser considerada modesta, pero de buena calidad, en que se valora La cooperación cientifica.

Palabra clave: salud mental; psico-dinámica del trabajo; portal de periódicos Capes/MEC; investigación bibliométrica.

\section{Résumé}

Cette recherche a eu l'objectif d'explorer le panorama des articles sur la psychodynamique du travail (PDT), parue au journal CAPES/ MEC, en langue portugaise, au cours de la période 2000 à 2014. Cette recherche est classée comme descriptif et bibliométrique. Pour trouver les articles, on a utilisé des mots-clés extraits de la théorie de la clinique du travail psychodynamique Quatre-vingt quinze (95) articles ont été localisés, ce qui correspond à une moyenne de 6,33 articles par an. Les résultats indiquent que la plupart des publications sont concentrés dans les années 2009 à 2012. Les articles peuvent être considérés comme bons, parce qu'ils ont été publiés, principalement, dans des périodiques avec Qualis / CAPES supérieur à B3. Parmi les thèmes principaux, il a été observé que les auteurs priorisent l'étude et l'analyse du travail, et sa relation avec la santé et la souffrance du travailleur. Quanto ao perfil dos autores verificouse que em sua maioria são do gênero feminino e com doutorado. En ce qui concerne la formation des réseaux de recherche, il a été identifié quatre (04) grands réseaux, où se détachent les régions Sudeste, Sul et Centro-Oeste comme les plus répresentatives. Il en résulte que la recherche en PDT peut être considérée comme modeste, mais de bonne qualité, et qui valorise la coopération scientifique.

Mots-clés: santé mentale; psychodynamique du travail; journal Capes/MEC; recherche bibliométrique.

Desde a década de 1950, os aspectos psicológicos do trabalho têm sido cada vez mais objeto de pesquisa, e essas pesquisas ganharam um novo impulso com o surgimento da investigação do ambiente psicossocial do trabalho e da psicologia do trabalho na década de 1960, cujo foco foi alterado para o impacto de certos aspectos do ambiente de trabalho na saúde (World Health Organization, 2008).

Segundo Dejours, Dessors e Desriaux (1993), é cada vez mais frequente se ouvir pesquisadores e médicos, nos colóquios sobre as condições de trabalho, falarem de deterioração/desgaste pelo trabalho, de envelhecimento precoce, mas isso não nos deve fazer perder de vista que o trabalho é, também, um fator essencial para nosso equilíbrio e de nosso desenvolvimento. Os mesmos autores afirmam que, para compreender as relações complexas entre a saúde e o trabalho, é preciso, antes de tudo, entender bem o que é, realmente, a saúde. Para a Organização Mundial da Saúde, a saúde é um estado de completo bem-estar físico, mental e social, e não consiste somente em uma ausência de doença ou enfermidade. Nessa perspectiva, a saúde não seria um estado, mas um objetivo.

As exigências excessivas do trabalho levam a um desgaste precoce tanto físico quanto psíquico. $\mathrm{O}$ trabalhador, para manter seu desempenho e a produtividade, sobrecarrega seu organismo, ficando mais vulnerável a quadros de adoecimento. Os distúrbios osteomusculares e as lesões por esforços repetitivos - DORT/LER, além dos transtornos psíquicos, são hoje as principais causas de afastamento no trabalho e de aposentadoria precoce, com forte impacto nas contas do sistema previdenciário (Almeida \& Lima, 2014; Lancman, Barros, Manna, \& Azevedo, 2015; Lancman \& Jardim, 2004).

Dejours (2009) tem uma visão ampliada sobre a causa desses desgastes. Segundo ele, a deterioração da saúde mental no trabalho está intrinsecamente ligada à evolução da organização do trabalho e, em particular, à introdução de novas estratégias, destacando-se a avaliação individualizada dos desempenhos, a busca da qualidade total, a terceirização em escala e o uso crescente de trabalhadores freelancer substituindo o trabalho assalariado. $\mathrm{O}$ aumento das patologias mentais 
ligadas ao trabalho resulta essencialmente da fragilização gerada por métodos organizacionais que, no lugar da confiança, da lealdade e da solidariedade, instalam no mundo do trabalho o cada um por si, a deslealdade, a desestruturação do convívio, produzindo uma implacável solidão em meio à multidão.

Contudo, é importante frisar que o trabalho é mais do que um ato de trabalhar. O trabalho tem uma função psíquica: é um dos grandes alicerces da constituição do sujeito e de sua rede de significados. Consoante Lancman (2011), processos como reconhecimento, gratificação, mobilização da inteligência, mais do que relacionados à realização do trabalho, estão ligados à constituição da identidade e da subjetividade do indivíduo.

Entre as diversas disciplinas que buscam refletir sobre as relações entre a saúde/doença mental e o trabalho, encontrase a psicodinâmica do trabalho (PDT), a qual constitui não é apenas uma abordagem clínica que visa evidenciar a relação entre o trabalho e os processos de subjetivação (Bendassolli \& Sobol, 2011), mas também uma teoria centrada na análise dos processos em causa na etiologia do sofrimento e das patologias, bem como do prazer e da saúde, relacionados com o trabalho. Uma das principais teses desta teoria foi formulada sob o nome de centralidade do trabalho para a subjetividade (Dejours \& Deranty, 2010). Para Lancmanet et al. (2015), a PDT debruça-se sobre a discussão entre saúde mental, trabalho e subjetividade. Os pesquisadores acrescentam que, dentre suas várias contribuições, está a de que o trabalho é um aspecto central para o desenvolvimento psíquico das pessoas.

Por conseguinte, esta pesquisa visa compreender o estado da arte das pesquisas realizadas estritamente no Brasil, abordando a relação entre a organização do trabalho, de um lado, e, do outro, a saúde mental no trabalho, considerando as premissas teóricas e metodológicas da PDT. Trata-se, portanto, de resolver a seguinte problemática: Qual é o quadro das pesquisas em PDT no país, e quais são as características dos autores atuantes nesta área?

O objetivo principal deste artigo é apresentar o panorama atual da pesquisa em clínica do trabalho no Brasil com o emprego do aporte teórico-metodológico de Dejours, tomando por base o banco de dados disponibilizado a toda a comunidade acadêmica e a sociedade em geral pelo Governo Federal, via Portal de Periódicos da Coordenação de Aperfeiçoamento de Pessoal de Nível Superior (CAPES)/Ministério da Educação (MEC), doravante chamado de Portal de Periódicos CAPES/MEC.

Decidiu-se, também, por investigar, em primeira ordem, apenas os trabalhos genuinamente brasileiros, para permitir aos interessados pelo tema saúde mental no trabalho e/ou na relação entre organização do trabalho e o trabalhar em si, sob a ótica do sofrimento e prazer no trabalho, verem um quadro das publicações científicas em periódicos, contendo detalhes sobre o número, a quantidade e qualidade dos artigos, bem como os polos científicos mais ativos em PDT, descortinando possíveis redes científicas estabelecidas entre as instituições e autores. De acordo com Lo Bianco, Almeida, Koller e Paiva (2010), 73\% dos artigos em Psicologia Organizacional e do Trabalho (PO\&T) foram publicados em periódicos nacionais. Os detalhes a serem apurados nesta pesquisa, possivelmente, possibilitarão a realização de comparações e apreciações entre o que vem se fazendo aqui e os trabalhos semelhantes existentes em outros locais, especialmente, na França, onde a PDT foi criada e desenvolvida.

Adiciona-se como justificativa para a pesquisa o número inexpressivo de trabalhos estatísticos, ou não, de cunho bibliométrico, sobre a produção em PDT ou em psicologia do trabalho e das organizações, como Oleto, Melo e Lopes (2013) e Borges-Andrade e Pagotto (2010).

\section{Referencial Teórico}

O trabalho é um dado fundamental da saúde, não somente de maneira negativa, quando é fonte de doenças, intoxicações, acidentes, desgastes etc., mas também de forma positiva. $\mathrm{O}$ (a) trabalhador(a) não chega ao trabalho como uma máquina nova, porque ele(a) tem uma história pessoal, que se concretiza por uma certa quantidade de aspirações, desejos, motivações e necessidades psicológicas. Em função de sua história, dispõe de vias de descarga preferenciais, que não são as mesmas para todos e que participam na formação daquilo que se chama estrutura da personalidade (Dejours, 2013).

Em se tratando da carga psíquica, o perigo principal é o a subutilização ou o a repressão das aptidões psíquicas, fantasiosas ou psicomotoras, pois ocasiona uma retenção de energia pulsional (tensão nervosa). Se o trabalho favorece esse livre funcionamento, ele será fator de equilíbrio, mas, se ele se opõe, será fator de sofrimento e de doença. Um trabalho em que não há grande coisa, mas em que é preciso estar presente e fazer de conta que se está ocupado, irá gerar rapidamente um aumento da carga psíquica, seguida por uma intensa fadiga (Dejours et al.,1993).

Nesse sentido, faz-se necessário discutir a organização do trabalho, porque é ela a origem do prazer (quando permite a quem trabalha empregar o saber-fazer, ter autonomia e reconhece o fruto do labor dos trabalhadores) ou do sofrimento (quando, ao contrário, impede aqueles que trabalham de empreender sua criatividade no desenvolvimento de suas atividades e isola-os do convívio com os outros).

Em função disso, segundo Dejours e Abdoucheli (2013), a organização do trabalho foi conceituada pelo contraste com as condições do trabalho. Por condições de trabalho entende-se os ambientes físicos (temperatura, pressão, barulho, 
vibração, irradiação, altitude etc.), mecânicos (condições de higiene, segurança e características antropométricas do posto de trabalho), químicos (produtos manipulados, vapores e gases tóxicos, poeiras, fumaças etc.) e biológicos (vírus, fungos, bactérias e parasitas) do posto de trabalho (Dejours, 1992, 2015a; Dejours \& Abdoucheli, 2013).

As pressões ligadas às condições de trabalho têm por alvo principal o corpo dos trabalhadores, podendo ocasionar desgaste, envelhecimento e doenças somáticas. Diferentemente, a organização do trabalho é, de um lado, a divisão das tarefas, que conduz alguns indivíduos a definirem por outros o trabalho a ser executado, o modo operatório ou de execução, e o ritmo a observar; e, por outro lado, é a divisão dos homens, isto é, o dispositivo de hierarquia, de supervisão, de comando, que define e codifica todas as relações de trabalho (Dejours, 1992, 2015a).

Quando se coloca face a face o funcionamento psíquico e a organização do trabalho, descobre-se que certas organizações são perigosas para o equilíbrio psíquico, pois atacam e destroem o desejo dos trabalhadores. Por exemplo, num trabalho repetitivo sob pressão de prazo, ou no trabalho por peças, não há absolutamente lugar para a atividade fantasiosa, de forma que as aptidões fantasiosas não são utilizadas e a via de descarga psíquica permanece fechada. A energia psíquica se acumula, se transformando em fonte de tensão e desprazer, até que aparece a fadiga, depois a astenia e, a seguir, a patologia. Portanto, as organizações favoráveis à saúde são aquelas que oferecem um campo de ação, um terreno em que o trabalhador concretiza suas aspirações, suas ideias, sua imaginação, seu desejo. Em geral, essa situação é possível quando o trabalho é livremente escolhido e quando a organização do trabalho é suficientemente flexível para que o trabalhador possa organizá-lo e adaptá-lo aos seus desejos, às necessidades de seu corpo, às variações de seu estado de espírito (Dejours et al., 1993).

Segundo Dejours e Abdoucheli (2013) se, por um lado, as condições de trabalho têm por alvo principalmente o corpo, a organização do trabalho, por sua vez, atual sobre o funcionamento psíquico. As divisões de tarefas e o modo de realizá-las incitam o sentido e o interesse do trabalho para o sujeito, enquanto a divisão de homens e mulheres solicita especialmente as relações entre pessoas, mobilizando os investimentos afetivos, o amor e o ódio, a amizade, a solidariedade, a confiança, etc. O próprio Dejours (2015a) assevera que a organização do trabalho talvez inscreva seus efeitos de maneira mais forte nas possibilidades de tratamento de uma doença mental do que em seu determinismo.

A psicodinâmica do trabalho teve suas origens em meados dos anos 80 , quando Christophe Dejours se voltou para o estudo da psicopatologia do trabalho na França, propondo uma teoria crítica para estudar o trabalho. No Brasil, ela foi inaugurada com o lançamento do livro traduzido A Loucura do Trabalho, de Dejours, cujo original em francês Travail: Usure Mentale foi lançado em 1987. Configura-se, atualmente, como uma abordagem autônoma, com métodos e pressupostos teóricos próprios, mas que ainda assim se encontra aberta para sugestões e questionamentos (Duarte \& Mendes, 2013). A preocupação da clínica psicodinâmica do trabalho, segundo Duarte \& Mendes (2013), é compreender o que move psíquica e socialmente o sujeito ao prazer no trabalho. Para Molinier (2003), a psicodinâmica do trabalho é a análise dos processos psíquicos mobilizados pelo encontro entre o sujeito e as imposições geradas pelos processos de trabalho.

Foi por intermédio das pesquisas realizadas que a PDT conseguiu demonstrar que a qualidade do trabalho vem do engajamento subjetivo dos indivíduos, quando ela pode se fundir sobre uma concepção compartilhada do sentido dado para a atividade realizada, quando os membros da equipe de trabalho podem confrontar seus modos operatórios ou execução da atividade e suas habilidades em espaços dedicados a esta discussão, e estabelecem de forma conjunta regras de trabalho, que são aceitas e praticadas por todos eles (Dejours, 2015b).

Mudando o foco para a discussão acerca de trabalhos científicos já realizados sobre dados bibliométricos envolvendo temas tratados pela abordagem de Dejours, com o objetivo de compreender detalhes desses estudos em nível Brasil, na pesquisa exploratória, de cunho bibliográfico, tomou-se contato com os trabalhos listados na seção da Introdução, os quais serão trabalhados nos parágrafos seguintes.

Oleto et al. (2013) empreenderam uma análise bibliométrica da produção sobre o prazer e sofrimento no trabalho nos anais do EnANPAD, Encontros da Associação Nacional de Pós-Graduação em Administração, no período de 2000 a 2010. Durante esse período, segundo os autores, foram apresentados 7.962 trabalhos em todas as divisões do EnANPAD. Desse total, apenas 26 artigos se propuseram a abordar o tema prazer e sofrimento no trabalho. Além dos 26, mais 6 artigos foram analisados, porque levavam algumas das palavras-chave no seu corpo. Na análise bibliométrica, os autores perceberam que os anos que mais tiveram trabalhos foram 2006 (4), 2007 (6) e 2009 (5); o autor mais citado foi Christophe Dejours, e, além dele, apareceram nas referências de todos os artigos Mendes (1999) e Codo, Soratto e Vasques-Menezes (2004). Os outros resultados alcançados foram: 1) as vivências de prazer estão ligadas ao reconhecimento, à flexibilização, aos desafios e ao poder; 2) o sofrimento se atrela ao contexto organizacional, às relações interpessoais e à rigidez das normas e regras das organizações; 3) as pressões sofridas pelos sujeitos no ambiente de trabalho são compensadas por essas estratégias defensivas.

Já Borges-Andrade e Pagotto (2010) estudaram o estado da arte da pesquisa brasileira em psicologia do trabalho e organizacional. Ao final, os autores concluíram que a produção intelectual em psicologia organizacional e do trabalho (PO\&T), ou psicologia do trabalho e das organizações (PT\&O), precisa ser mais divulgada por meio de veículos dela própria e da psicologia, sem abandonar os veículos da administração. Os autores comentaram que também devem citar mais artigos 
nacionais, que a produção precisa ser mais bem distribuída entre autores e estes devem mantê-la ao longo de suas vidas. Eles alertam que os docentes devem ser estimulados a cooperar para desenvolver artigos. Por fim, comentaram que a produção, além da divulgação em periódicos científicos, precisará ser traduzida, para ser compreendida por audiências formada por gestores, trabalhadores e público em geral, e disseminada em meios que alcancem tais audiências com ligeireza e singeleza.

\section{Detalhes sobre o Método de Pesquisa}

Para consecução do objetivo de levantar o panorama dos artigos nacionais sobre PDT, optou-se por examinar os trabalhos publicados no Portal de Periódicos CAPES/MEC, por ser um veículo importante no cenário brasileiro de divulgação de pesquisas científicas, seja em bases de dados e periódicos, seja de produtos originários de programas de pós-graduação stricto sensu. A pesquisa foi realizada no período compreendido entre 2000 e 2014, 15 anos portanto.

Empregaram-se as seguintes palavras-chave no levantamento dos artigos: "Psicodinâmica do Trabalho", "Clínica Psicodinâmica do Trabalho", "Análise Psicodinâmica do Trabalho", "Reconhecimento no Trabalho" e "Vivência de Prazer e Sofrimento".

Para a análise e interpretação dos dados, visando atingir o objetivo da pesquisa, uma pesquisa descritiva foi realizada, a qual, consoante Gil (2011), adota como principal objetivo descrever as características de determinada população, fenômeno ou, ainda, estabelecer relações entre as variáveis. E ainda uma análise bibliométrica foi operacionalizada.

Depreende-se por bibliometria o estudo de aspectos quantitativos da produção, disseminação e uso de informações registradas. Esta técnica analisa, entre outras coisas, as características dos autores e das fontes de publicação, o crescimento ou obsolescência de literaturas, base de dados e outras fontes de informação, bem como analisa tendências de utilização dessas informações (Tague-Sutcliffe, 1992).

Dessa forma, para a análise quantitativa da produção em PDT durante o período de pesquisa já evidenciado, foram examinados 95 artigos nacionais, número apurado mediante a pesquisa feita no Portal de Periódicos CAPES/MEC com as palavras-chave apresentadas no início desta seção.

Escolheu-se o Portal de Periódicos CAPES/MEC por ser uma biblioteca virtual, que disponibiliza para as instituições de ensino e pesquisa do Brasil a melhor produção científica nacional e internacional, tendo em seu acervo mais de trinta e seis mil títulos com textos completos, e cento e trinta bases referenciais. Ele é considerado um modelo de consórcio de bibliotecas, único no mundo, pois é inteiramente financiado pelo governo brasileiro. É também a iniciativa do gênero com a maior capilaridade no planeta, cobrindo todo o território nacional (CAPES/MEC, 2015).

Para análise, foram coletadas, em todos os artigos, informações que podem ser enumeradas em dois grupos, como seguem:

Características das publicações, tais como: ano da publicação, periódico de publicação, número de artigos por sistema Qualis/ Capes $^{1}$, número de páginas dos artigos, número e tipo (nacionais e internacionais) de referências utilizadas e tema da publicação;

Perfil dos autores, envolvendo: quantidade de autores, titulação, gênero, filiação institucional e região geográfica.

Ressalta-se que os dados atinentes ao perfil dos autores, em sua maioria, foram auferidos no currículo lattes de cada pesquisador. Portanto, em função de alguns deles não manterem seu currículo atualizado e outros não o possuírem - embora fossem minoria - esse fato deve ser compreendido como uma das limitações do estudo em tela. Além da utilização do lattes, buscou-se, quando não encontradas os registros necessários naquele documento, pesquisar em sites, como Google e Yahoo, para completarem-se alguns dados importantes para a análise. Para os demais itens, todos foram extraídos dos próprios artigos.

Para análise e interpretação dos dados bibliométricos, diferentes técnicas foram empregadas. Em sua maioria, foram utilizadas técnicas de estatística descritiva, com o uso do software PASW Statistics 21. Contudo, quanto ao tema da publicação, foi necessário o emprego de uma nuvem de palavras, elaborada a partir do resumo dos artigos analisados, por intermédio do software online Tagul. E ainda, quanto ao perfil dos autores, optou-se, além das técnicas de estatística descritiva, por realizar uma análise sobre as redes de colaboração científica, construídas a partir do relacionamento entre autores, sua filiação e região geográfica a que pertencem. Para isso, foi utilizado o software Ucinet 6 .

Segundo Vanz (2009), a colaboração científica tem sido definida como dois ou mais cientistas trabalhando juntos em um projeto de pesquisa, compartilhando recursos intelectuais, econômicos e/ou físicos. Portanto, as redes de pesquisa -

1 Qualis é o conjunto de procedimentos utilizados pela Capes para estratificação da qualidade da produção intelectual dos programas de pósgraduação. A classificação de periódicos é realizada pelas áreas de avaliação e passa por processo anual de atualização. Esses veículos são enquadrados em estratos indicativos da qualidade - A1, o mais elevado; A2; B1; B2; B3; B4; B5; C - com peso zero (CAPES, 2015). 
colaboração científica - impulsionam a criação do conhecimento e o processo de inovação resultantes do intercâmbio de informações e, sobretudo, da junção de competências de grupos que unem esforços na busca de metas comuns (Balancieri, Bovo, Kern, Pacheco, \& Barcia, 2005).

\section{Apresentação e Discussão dos Resultados}

Para se chegar ao número de pesquisas científicas em PDT, primeiro, procedeu-se a busca no site de artigos científicos que contivessem as palavras-chave definidas pelos pesquisadores, individualmente. Aplicado tal procedimento, chegou-se a quase duas centenas de publicações. O passo seguinte foi realizar a revisão de títulos, resumos e documentos completos de cada um dos artigos que suscitaram dúvidas nos pesquisadores do seu enquadramento, excluindo-se do universo mapeado os estudos que não contemplavam, de fato, a temática investigada. Após esses dois procedimentos metodológicos, apurou-se, então, a amostra de artigos científicos ligados à teoria dejouriana.

Depois da consulta das palavras-chave no campo de busca do Portal de Periódicos CAPES/MEC, e da eliminação de artigos repetidos porque, embora tivesse em seu conteúdo umas das palavras-chave, não se tratava de pesquisas em PDT, apurou-se a quantidade de 95 documentos publicados no decorrer dos 15 anos, o que resulta numa média de 6,33 artigos por ano. Participaram como autores e coautores desses artigos o total de 179 pessoas. Em termos absolutos, isso daria 0,53 artigos por autor, mas não é essa a realidade, pois muitos deles produziram em 15 anos vários trabalhos e, outros, apenas um. Esse último caso constitui a maioria.

O baixo índice de artigos contraria um pouco o que foi previsto por Hutz, Rocha, Spink e Menandro (2010), pois, segundo eles, ao contrário de outras áreas das ciências humanas e sociais, na Psicologia, os livros e capítulos de livros são menos frequentes do que os artigos em periódicos. O atual sistema de avaliação dos programas da CAPES/MEC tende a valorizar mais estes que aqueles. Cabe fazer uma ressalva aqui sobre o objetivo da pesquisa de Hutz et al. (2010), que abordou área da Psicologia em geral, não apenas um campo ou subárea, o que talvez explique a diferença nos resultados. Para exemplificar mais, encontram-se vários livros e capítulos de livro, organizados por pesquisadores em PDT, como os de Mendes, Merlo, Morrone e Facas (2012), Macêdo (2015), Mendes e Araújo (2012), Monteiro, Vieira e Mendes (2015), Vieira, Mendes e Merlo (2013), Freitas (2013), apenas para citar alguns mais recentes, enquanto os artigos científicos, como visto, ainda não têm grande representatividade, pelo menos na base de dados pesquisada.

De acordo com Lo Bianco et al. (2010), em três avaliações trienais da CAPES, pode-se observar que houve um aumento significativo da produção bibliográfica dos docentes na área de Psicologia, sendo que no triênio 2004-2006 a média de artigos era de 1,75. Esse dado mostra um aumento significativo quando comparado com o valor do triênio 2001-2003, que foi de 1,31. Verificase que o número apurado nesta pesquisa, de 0,53 , considerando todos os autores, fica bem aquém do apurado na pesquisa de Lo Bianco et al. (2010), mas, para uma análise comparativa mais consistente, precisaria expurgar da relação dos 179 pesquisadores, que apareceram pelo menos uma vez nos artigos, todos aqueles desvinculados de programas de pós-graduação stricto sensu.

Como detalhado no capítulo de apresentação da trajetória metodológica deste estudo, os dados foram organizados levando-se em conta dois grandes grupos: características das publicações e perfil dos autores respectivamente, portanto os resultados e sua discussão serão apresentados respeitando essa sequência nos subcapítulos seguintes.

\section{Características das Publicações}

Foi possível apurar, por intermédio da distribuição de frequência dos artigos, que os anos com mais publicações em PDT foram 2011 (20\%), 2009 (16,8\%), 2012 (10,5\%), seguidos de 2004 e 2010 com 8,4\% cada um. O total de publicações nesses anos corresponde a $64,1 \%$ de toda produção do período analisado. Depreende-se, daí, que a produção se concentrou basicamente de 2009 a 2012, isto é, em 4 anos dos 15 analisados.

Diferentemente desta pesquisa, Tonetto, Amazarray, Koller e Gomes (2008), ao analisarem o volume de produções em psicologia organizacional e do trabalho nos principais periódicos de Psicologia, de 2001 a 2005, a partir do portal Scielo, enfatizaram o grande volume de trabalhos que buscavam compreender as relações entre modelos de gestão e formas de subjetivação e saúde mental, tanto na linha temática trabalho e saúde como na temática trabalho, identidade e subjetivação. Segundo os pesquisadores, tal interesse pode ser interpretado como um esforço, por parte de estudiosos da Psicologia, para compreender as implicações subjetivas decorrentes dos avanços tecnológicos e novos modos de gestão, como o modelo japonês, visto que tais modelos pressupõem maior envolvimento e participação dos trabalhadores. Em tais estudos, priorizam-se fatores da organização do trabalho que levam ao adoecimento, em detrimento de aspectos promotores da saúde mental. Considerando os artigos do portal e a delimitação para a PDT, somente o ano de 2004 mostrou-se condizente com os achados de Tonetto et al. (2008). 
Cabe observar que, para os últimos anos (2013 e 2014), teve-se um decréscimo considerável em relação ao número de produção científica, fato que mereceria maior análise, isoladamente, para apuração das causas dessa desaceleração científica em PDT, porque, se não houve aumento de programas de pós-graduação no período, por exemplo, os centros de pesquisas na área, em tese, continuaram os mesmos. Os anos com menores números de artigo foram 2005, com apenas 1 artigo, e 2014, com 2 artigos.

Esperava-se encontrar mais produções científicas no período, em função do grande crescimento do número de programas de pós-graduação stricto sensu em Psicologia, que oferecem cursos nos níveis de mestrado e doutorado. Segundo Lo Bianco et al. (2010), entre 1996 e 2007, esses cursos saltaram de 24 para 53, sendo que o maior crescimento $(35,8 \%)$ ocorreu entre 1998 e 2001. Como se pode ver, esse aumento de cursos não refletiu no aumento de produção, principalmente no Portal de Periódicos CAPES/MEC, para a PDT, indicando que os cursos priorizaram outras áreas e campos da psicologia, não a psicologia organizacional e do trabalho (PO\&T) ou a psicologia do trabalho e das organizações (PT\&O).

Quanto aos periódicos nos quais os artigos foram publicados, a revista Ciência \& Saúde Coletiva destacou-se com o maior índice de publicação relacionada à PDT, com 9,5\% (9 artigos); seguida pela revista Produção, com 7,4\% (7 artigos); e Psicologia \& Sociedade, com 6,3\% (6 artigos). A revista Ciência \& Saúde dedica-se a publicar debates, análises e resultados de investigação sobre tema específico considerado relevante para a Saúde Coletiva. Como o adoecimento no trabalho, especialmente envolvendo a parte mental e sua relação com a organização do trabalho, é um objetivo da PDT, depreende-se que faz sentido a revista ser procurada por pesquisadores do assunto.

O mesmo acontece com a Revista Psicologia \& Sociedade, por ser da Psicologia, área do conhecimento em que está a PDT. É curioso, porém, a Revista Produção enquadrar-se como a segunda mais visada pelos pesquisadores em PDT para divulgação de seus trabalhos, tendo em vista ser vinculada à área de Engenharia de Produção. Uma provável explicação é o fato de que a PDT buscou na ergonomia vários conceitos para consolidar parte da sua epistemologia e este assunto também é pesquisado na Engenharia de Produção.

Tonetto et al. (2008) realizaram pesquisa considerando periódicos brasileiros em Psicologia (rPOT, Psicologia \& Sociedade, Estudos de Psicologia - Natal, Psicologia em Estudo, Psicologia: Reflexão e Crítica, Psicologia: Teoria e Pesquisa, Psicologia - USP), que publicaram artigos relacionados a PO\&T. Eles encontraram 178 artigos, entre 2001 e 2005, correspondendo a $16 \%$ do total de artigos publicados nesses periódicos. Diagnosticaram essa produção como sendo grande e diversificada, com predomínio de temas relacionados ao comportamento organizacional (20\%); seguidos por avaliação e medidas; trabalho, identidade e subjetivação; trabalho, saúde e gestão de pessoas (cada um com 11\%). Comparando o resultado encontrado por Tonetto et al. (2008) com esta pesquisa, percebe-se que, das revistas objeto de estudo deles, somente uma delas, Psicologia \& Sociedade, apareceu em destaque na divulgação de estudos em PDT. As demais também apareceram, mas com poucos artigos.

Ainda com relação aos periódicos, constatou-se um número de 25 veículos que tiveram no curso de 15 anos somente uma publicação vinculada a abordagem de Dejours, evidenciando, destarte, grande dispersão na publicação de artigos relacionados à PDT. Em pesquisa de Borges-Andrade e Pagotto (2010), foi visto que até $70 \%$ da produção da pós-graduação em PT\&O, divulgadas em periódicos nacionais, ocorre em periódicos mantidos por entidades e cursos vinculados à área da Administração, e não de Psicologia, fato que pode ser uma explicação para a variedade de periódicos levantados neste artigo. A revista que mais se aproxima do tema em si (PDT), Rpot (Revista Psicologia: Organizações e Trabalho), teve somente um artigo localizado no período de análise. Outro aspecto analisado foi o número de artigos publicados em periódicos considerando-se sua estratificação de qualidade prevista pelo sistema Qualis. Os resultados obtidos estão descritos na Tabela 1.

Tabela 1

Qualis dos periódicos por artigo

\begin{tabular}{cccc}
\hline Qualis & Frequência & \% & \% Cumulativo \\
\hline A1 & 2 & 2,1 & 2,1 \\
A2 & 35 & 36,8 & 38,9 \\
B1 & 23 & 24,2 & 63,2 \\
B2 & 22 & 23,2 & 86,3 \\
B3 & 3 & 3,2 & 89,5 \\
B4 & 5 & 5,3 & 94,7 \\
S/ classificação & 5 & 5,3 & 100,0 \\
\hline Total & 95 & 100,0 &
\end{tabular}


As informações mostradas na tabela 1 indicam a concentração dos artigos em periódicos com Qualis superior a B3, sendo 2,1\% (A1); 36,8\% (A2); 24,2\% (B1); e 23,2\% (B2). Portanto, 86,3\% das publicações analisadas foram publicadas em periódicos de boa a excelente qualidade para fins científicos.

Embora o número de produções científicas apresentado no Portal de Periódicos CAPES/MEC ${ }^{2}$ seja modesto em termos gerais - pelo menos nas bases de dados estudadas -, a qualidade dos trabalhos é algo a ser destacada, não obstante haver apenas 2 trabalhos, em 15 anos, com pontuação máxima de qualidade, isto é, com Qualis A1. Essa baixa produção dá sentido a um comentário feito por Borges-Andrade e Pegotto (2010), os quais, estudando o campo da PT\&O em programas de pósgraduação stricto sensu em Psicologia no Brasil, constataram que ele constituía uma das duas maiores lacunas nacionais.

Das informações da Tabela 1, dois outros fatos merecem destaque. O primeiro deles é que, em 15 anos, nenhum trabalho foi publicado em revista enquadrada como B5. Segundo, que há envio de artigo para periódico sem registro no sistema Qualis, não obstante o número ser inexpressivo no contexto (5 artigos). Este último fato foi observado por Lo Bianco et al. (2010), segundo os quais, embora tenha-se verificado crescimento na produção bibliográfica dos programas do pósgraduação em psicologia, ainda é comum um número significativo de artigos publicados em revistas qualificadas como nacional $\mathrm{C}$ e mesmo em revistas locais.

O próximo assunto da análise foi a existência de parceria acadêmica entre autores para elaboração de artigos científicos. Para mostrar esse cenário, elaborou-se a Tabela 2.

Tabela 2

Número de autores por artigo

\begin{tabular}{cccc}
\hline Quantidade de autores & Frequência & \% & \% Cumulativa \\
\hline 1 & 16 & 16,8 & 16,8 \\
2 & 48 & 50,5 & 67,4 \\
3 & 18 & 18,9 & 86,3 \\
4 & 9 & 9,5 & 95,8 \\
5 & 4 & 4,2 & 100,0 \\
\hline Total & 95 & 100,0 & \\
\hline
\end{tabular}

Conforme a tabela 2, 83,2\% (100\% menos 16,8\%) dos artigos analisados foram elaborados em parcerias. Dos níveis de parcerias encontrados, entre 2 a 5 autores, evidencia-se uma preferência de publicação com $2(50,5 \%)$ e $3(18,9 \%)$ autores respectivamente. Destaca-se ainda que, do total de publicações, apenas $16,8 \%$ foram realizados por um único autor. As parcerias também foram observadas em estudo de Rossoni (2006) sobre a produção em comportamento e gestão organizacionais, em cujo trabalho ela mencionou que cresceu a cooperação entre autores em geral e que eles estão mais produtivos. Analisou-se ainda as características dos trabalhos relacionadas à quantidade e tipos de referências, bem como o número de páginas, elaborando-se a Tabela 3 para evidenciar o resultado.

O Portal de Periódicos CAPES/MEC, para a área de ciências humanas, subcategoria de Psicologia, compreende as seguintes bases de dados: Cognitive Sciences Eprint Archive : CogPrints, Index Psi Periódicos : IndexPsi, Núcleo Brasileiro de Teses e Dissertações em Educação, Educação Física, Educação Especial, Pepsic - Periódicos Eletrônicos em Psicologia, Psycoloquy,Repositório Científico de Acesso Aberto de Portugal (RCAAP), SciELO. ORG, DOAB: Directory of Open Access Books, e UNIVATES. Biblioteca Digital. 
Tabela 3

Características dos artigos quanto ao número de referências e páginas

\begin{tabular}{ccccccc}
\hline Descrição & N de artigos & Quantidade & Média & Desvio padrão & Mínimo & Máximo \\
\hline Referências Nacionais & 95 & 1.929 & 20,305 & 10,3914 & 0,0 & 48,0 \\
Referências Internacionais & 94 & 528 & 5,62 & 7,285 & 0,0 & 49,0 \\
Referências Totais & 95 & 2.457 & 25,863 & 11,1552 & 4,0 & 70,0 \\
Número de Páginas & 95 & 1.166 & 12,274 & 5,5571 & 2,0 & 28,0 \\
\hline
\end{tabular}

Segundo as informações demonstradas na tabela 3, observa-se que, em média, os artigos utilizam cerca de 20 referências nacionais, chegando a um número máximo de 48 referencias usadas em sua construção. Para as referências internacionais, verifica-se que, dos 95 artigos analisados, 94 fizeram uso desse tipo de referência, contudo, sua média de utilização é bem inferior às nacionais. Em média, os artigos utilizam 5,62 referências internacionais. Ao analisar-se o conjunto de todas as referências bibliográficas adotadas nos artigos pesquisados, constata-se que, em média, utilizam em torno de 26 referências totais. Quanto ao número de páginas, os artigos pesquisados possuem em média 12 páginas, sendo o número mínimo de 2 páginas e o número máximo de 28 páginas.

A predominância do tipo de referências (nacionais) empregado pelos pesquisadores brasileiros ao fazerem seus estudos em PDT não guarda relação com as referências dos artigos publicados na área de PO\&T, porque, de acordo com Tonetto et al. (2008), nas referências bibliográficas dos artigos da área apareceram 36\% de autores nacionais e igual percentual de autores internacionais, e as referências mistas representaram 29\%. Logo, nas pesquisas acadêmicas de PO\&T, em geral, os pesquisadores utilizam mais artigos internacionais do que os específicos de PDT.

Ainda quanto às características gerais dos trabalhos analisados, optou-se por investigar quais são os principais subtemas relacionados à PDT. Para isso, elaborou-se uma nuvem de palavras a partir dos resumos dos artigos, cujo objetivo foi mensurar a frequência das palavras utilizadas pelos autores. Os resultados podem ser verificados na Figura 1.

A figura 1 evidencia as principais palavras utilizadas na construção dos resumos dos artigos pesquisados. As palavras mais frequentes nestes resumos são: trabalho, saúde, sofrimento, trabalhador, processo, psicodinâmica, organização e prazer, nesta ordem. Essas palavras estão diretamente correlacionadas com a temática principal, a PDT, como também, como mostram as quatro palavras mais frequentes, priorizam o estudo e análise do trabalho, e a sua relação com a saúde e sofrimento do trabalhador.

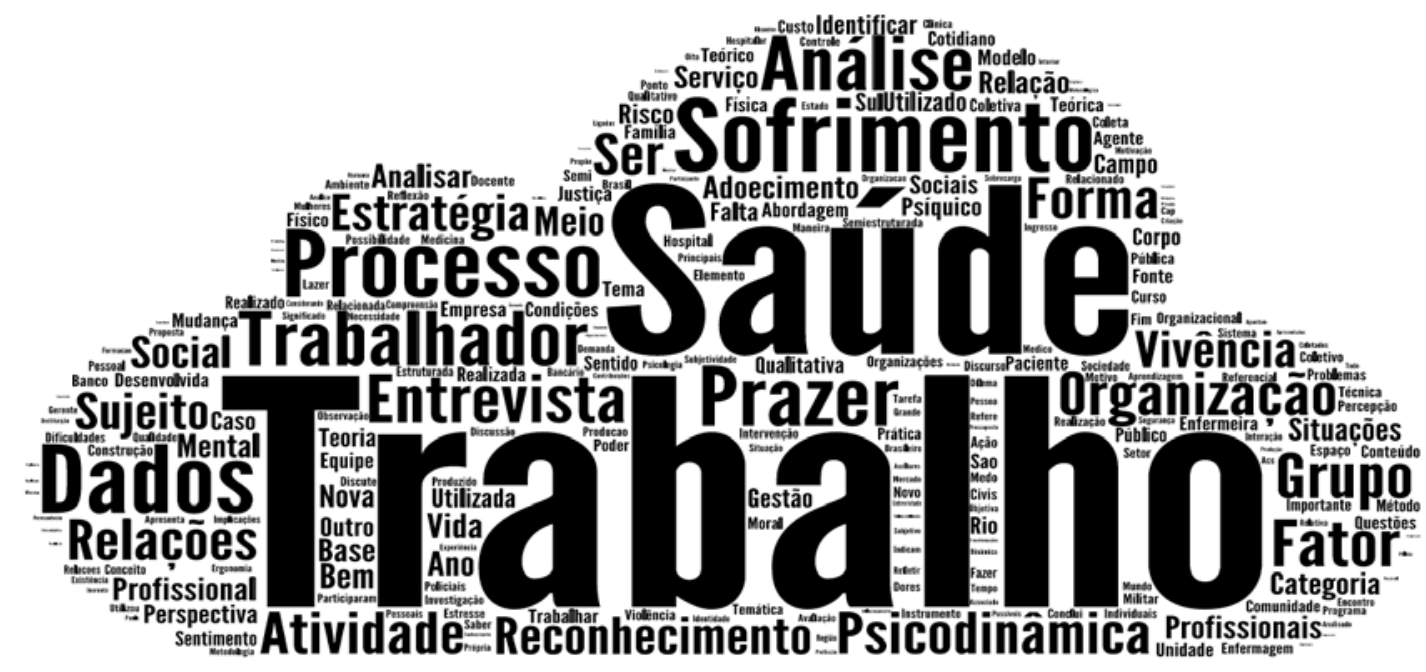

Figura 1. Nuvem de palavras. 


\section{Perfil dos Autores}

Para a análise do perfil dos autores agrupou-se a totalidade deles, não importando a ordem de autoria, para extração de informações sobre sexo, titulação, quantidade de produção e, ainda, as relações existentes de cooperação científica, suas instituições e regiões geográficas. A Tabela 4 apresenta os resultados para o sexo dos autores.

Tabela 4

Gênero dos autores

\begin{tabular}{cccc}
\hline Gênero & Frequência & \% & \% Cumulativo \\
\hline Feminino & 139 & 77,2 & 77,2 \\
Masculino & 41 & 22,8 & 100,0 \\
\hline Total & 180 & 100,0 & \\
\hline
\end{tabular}

Segundo as informações da Tabela 4, a maioria dos autores, cerca de $77,2 \%$, pertencem ao sexo feminino, enquanto $22,8 \%$ ao sexo masculino. Dessa forma, infere-se que, segundo os dados da pesquisa, as publicações em PDT no Brasil, em sua maioria, são elaboradas por autores do sexo feminino. Esta predominância confirma Borges-Andrade e Pagotto (2010), que citaram pesquisas de Gondim e Bastos $(2009,2010)$ sobre a atuação de psicólogos no campo do trabalho e das organizações, mostrando que a participação das mulheres nesta área é de 83\%. Para a titulação dos autores foi elaborada a Tabela 5.

Tabela 5

Titulação dos autores

\begin{tabular}{cccc}
\hline Titulação & Frequência & \% & \% Cumulativo \\
\hline Doutorado & 118 & 65,6 & 65,6 \\
Mestrado & 46 & 25,6 & 91,1 \\
Especialista & 3 & 1,7 & 92,8 \\
Graduação & 9 & 5,0 & 97,8 \\
Não localizado & 4 & 2,2 & 100,0 \\
\hline Total & 180 & 100 & \\
\hline
\end{tabular}

Pela Tabela 5 observa-se que a maioria dos autores possui doutorado, 65,6\% do total. Verifica-se ainda que $91,1 \%$ dos autores possuem alto grau de titulação, com mestrado e doutorado. Assim sendo, pode-se inferir que a publicação em PDT concentra-se efetivamente em cursos de mestrado e doutorado, e acontece após a defesa dos trabalhos, uma vez que o número de autores com título de especialista ou graduação é bastante inexpressivo.

A análise da rede de cooperação científica entre os autores, além de permitir identificar como essas redes são formadas, permite a visualização dos autores mais prolíficos. A Figura 2 apresenta essa rede de cooperação. 
Figura 2. Rede de cooperação entre autores.

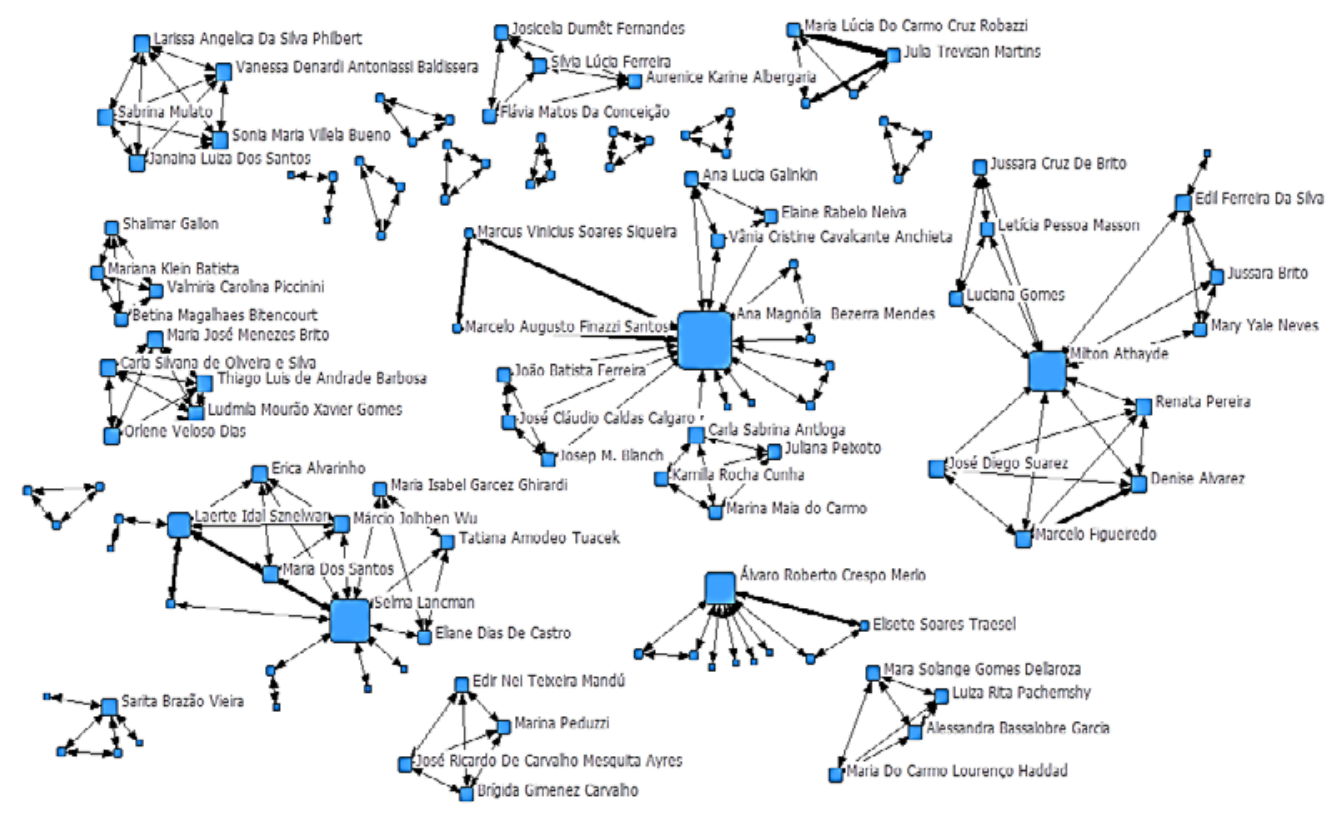

Nota: Para a elaboração da rede de cooperação foram extraídos nós isolados e nós pendentes (com grau 1 para uma melhor visualização das redes de cooperação.

A Figura 2 permite identificar como se dá a formação de redes de cooperação científica. Entre os autores de PDT, segundo os dados dos artigos analisados, observa-se a existência de quatro grandes redes de cooperação, em que os nós principais dessas redes são os autores Ana Magnólia Bezerra Mendes, Milton Athayde (não pesquisa diretamente em PDT), Selma Lancman e Álvaro Roberto Crespo Merlo.

A primeira e maior rede, formada pela professora Ana Magnólia Bezerra Mendes, apresenta a existência de uma cooperação mais intensa entre essa autora e os autores Marcelo Agusto Finazzi Santos e Marcus Vinícius Soares Siqueira. Verifica-se que esta professora, além de possuir a maior rede de cooperação científica entre os autores analisados, ainda é a mais produtiva, com total de 9 publicações. Destaca-se que, dentre as maiores redes, essa ainda conta com a participação de um autor internacional, Josep Maria Blanch.

A segunda maior rede de cooperação científica é formada pelo professor Milton Athayde. Apesar do tamanho da rede, este autor não foi classificado como o segundo mais prolífero pelo fato de possuir somente 4 publicações, mesmo número dos pesquisadores Laerte Idal Sznelwar e Júlia Trevisan Martins.

A terceira maior rede de cooperação científica é liderada pela professora Selma Lancman. Essa rede apresenta tamanho similar à segunda rede. Observa-se, quando comparados com os outros autores da rede, a existência de parceria mais solidificada entre essa autora e a professora Maria dos Santos. Ressalta-se que a autora Selma Lancman também está em terceiro lugar em produtividade, com 6 publicações.

O autor líder da quarta maior rede de cooperação científica é o professor Álvaro Roberto Crespo Merlo. Segundo verifica-se na figura 2, com os autores que compõem a rede prevalece a parceria com a profa. Elisete Soares Traesel sobre as demais. Apesar de ser o quarto em relação ao tamanho de sua rede de cooperação, destaca-se que, em produtividade, este autor é o segundo mais produtivo, com 7 publicações do total de 95 artigos analisados.

A Figura 3 evidencia a rede de cooperação científica entre instituições e suas respectivas regiões geográficas. 
Figura 3. Rede de cooperação entre instituições e região geográfica.

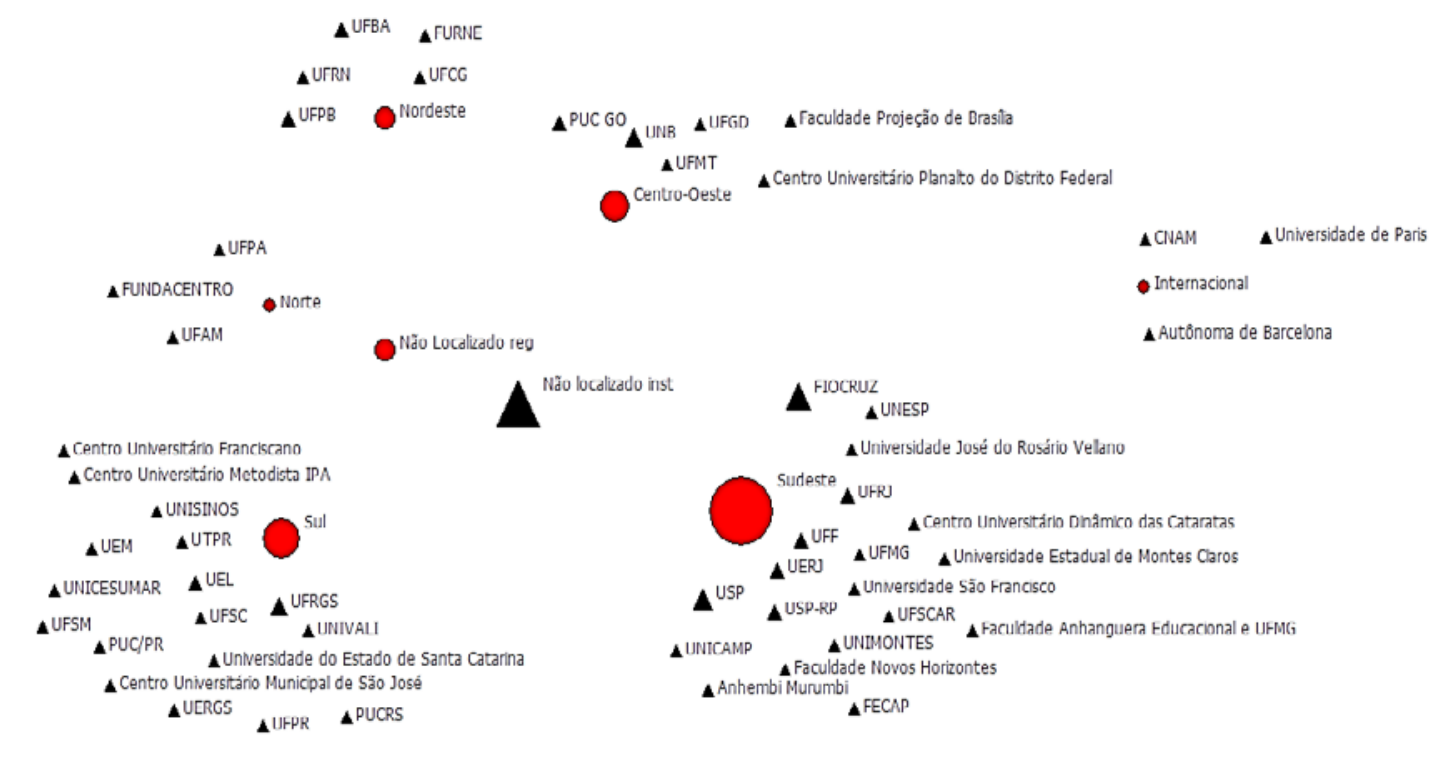

Ao analisar a rede de cooperação científica entre instituições e suas respectivas regiões geográficas percebe-se que a região geográfica com maior número de cooperações é a região sudeste, seguida pela região sul, centro-oeste e nordeste. De acordo com o Borges-Andrade e Pagotto (2010), a região sudeste concentra 49\% das mulheres que militam no campo do "trabalho" e das "organizações", o que de certa forma confirma os dados desta pesquisa, mesmo que, no estudo deles, o tema tenha sido abordado em termos gerais a respeito da atuação do Psicólogo, diferentemente deste estudo, que trata de autores de trabalhos científicos. Mas, como se vê, tem grande semelhança, visto que foram destaque nos dois estudos tanto o sexo quanto a região.

Aregião Sudeste possui um total de 18 instituições, dentre essas, a região contempla ainda a instituição com a maior relação de cooperação científica, a FIOCRUZ, quando comparada com as demais instituições. Destacam-se ainda a Universidade de São Paulo (USP), Universidade Federal Fluminense (UFF), Universidade Federal do Rio de Janeiro(UFRJ), Universidade do Estado do Rio de Janeiro (UERJ) e Universidade de São Paulo, campus Ribeirão Preto (USP-RP). A segunda maior rede de cooperação científica, a região Sul, apresenta um total de 17 universidades e centros universitários, sendo as instituições que mais se destacam, por sua interação com outras instituições, a Universidade Federal do Rio Grande do Sul (UFRGS), a Universidade Estadual de Londrina (UEL) e a Universidade do Vale do Itajaí (UNIVALI). Já na região Centro-Oeste, terceira maior em termos de cooperação científica, destacam-se a Universidade de Brasília (UNB) e a Pontífica Universidade Católica de Goiás (PUC-GO). Enquanto na região Nordeste, quarta em termos de colaboração científica, as instituições mais expressivas em redes de colaboração são a Universidade Federal da Bahia (UFBA), Fundação Universitária de Apoio ao Ensino, à Pesquisa e à Extensão (FURNE) e Universidade Federal de Pernambuco (UFPB).

$\mathrm{O}$ resultado apresentado da colaboração científica entre instituições por região geográfica, quando comparado com a quantidade de cursos de pós-graduação stricto sensu na área de Psicologia atualmente (CAPES, 2016), parece indicar que o número deles influencia no tamanho da rede de colaboração. De acordo com os dados da CAPES (2016), as regiões que têm mais cursos de mestrado e doutorado são Sudeste, Sul, Nordeste e Centro-Oeste, respectivamente; portanto, tal cenário assemelha-se ao encontrado no tamanho das redes de colaboração, exceto para região Nordeste. Depreende-se, então, que essa região, pelo fato de ter mais cursos stricto sensu, em Psicologia do que as regiões Centro-Oeste e Norte, poderá, em futuras investigações, aparecer com maior destaque em relação ao que fora apresentado nesta pesquisa.

Em aspectos gerais, as redes de cooperação entre instituições e região geográfica apuradas e comentadas acima, elaboradas a partir dos artigos publicados em PDT em 15 anos, corrobora os resultados auferidos por Tonetto et al. (2008), os quais investigaram o desenvolvimento científico em psicologia organizacional e do trabalho no Brasil, no período de 2001 a 2005 , tomando por base os periódicos indexados no Portal Scielo. De acordo os pesquisadores, as universidades que apresentaram maior volume de publicações na área foram a UNB, a UFSC, a UFRGS, a Universidade Federal do Rio Grande do Norte (UFRN), a UFBA, a Universidade de Aveiro/Portugal e a PUC-GO. Logo, todas pertencentes às regiões brasileiras elencadas nesta pesquisa.

Cabe destacar também que Tonetto et al. (2008) restringiram sua análise para comentar sobre artigos envolvendo temas como trabalho, identidade e subjetivação, além de trabalho e saúde. As universidades que se destacaram neste contexto foram 
UFRGS, UFF, UNB, portanto, representantes da região Sul, Sudeste e Centro-Oeste, nesta ordem, igualmente ao que foi apurado e demonstrado neste artigo.

A região Norte não apareceu de forma destacada, embora conte com um laboratório de psicodinâmica do trabalho na Universidade Federal do Amazonas, criado em 2010. Provavelmente, em pesquisas futuras com características bibliométricas, essa região deve constar, sobretudo, porque, em consonância com Martins et al., (2013), tal laboratório já desenvolveu 13 pesquisas e tem em andamento outras 5. Esses mesmos autores oferecem informações importantes, as quais podem explicar o porquê do não aparecimento da rede de forma destacada nesta pesquisa, como o fato de que suas pesquisas geraram livros e/ ou capítulos de livros. Como este estudo concentrou sua análise em artigos científicos, as produções dos pesquisadores ligados a esse laboratório não geraram uma rede expressiva.

\section{Conclusão}

O objetivo da pesquisa foi levantar o panorama dos artigos sobre psicodinâmica do trabalho (PDT) disponibilizados para a comunidade científica, em língua portuguesa, no Portal de Periódicos CAPES/MEC, no período de 2000 a 2014.

Conclui-se que o objetivo da pesquisa foi alcançado, pois os dados permitiram evidenciar que a pesquisa em PDT pode ser considerada como modesta, de boa qualidade, em que seus autores são predominantemente do gênero feminino, e possuem título de doutorado. Os autores mais prolíficos foram Ana Magnólia Bezerra Mendes, Álvaro Roberto Crespo Merlo e Selma Lancman. Os resultados ainda evidenciaram que, na realização de suas pesquisas, os autores priorizam as redes de colaboração científica, e estas estão principalmente situadas nas regiões sudeste, sul e centro-oeste.

Observa-se a utilização de uma única fonte de pesquisa, o Portal de Periódicos CAPES/MEC, foi uma das limitações da pesquisa, assim como a análise de artigos em língua portuguesa. Sugerem-se para futuras pesquisas, a realização de uma pesquisa bibliométrica que contemple outras bases de dados, como Scielo, Elsevier e Google acadêmico, como também a utilização de artigos internacionais, o que permitirá uma confrontação entre o estado da arte de pesquisas nacionais e internacionais em psicodinâmica do trabalho.

\section{Referências}

Almeida, D. R., \& Lima, G. S. (2014). Conhecendo os principais sintomas da doença osteomuscular (LER-DORT) que acometem profissionais de enfermagem de uma clínica do Hospital Regional de Cáceres Doutor Antônio Fontes, Mato Grosso, Brasil. Gestão e Saúde, 5(esp.), 2607-2631.

Balancieri, R., Bovo, A. B., Kern, V. M., Pacheco, R. C. S., \& Barcia, R. M. (2005). A análise de redes de colaboração científica sob as novas tecnologias de informação e comunicação: um estudo na Plataforma Lattes. Ciência da Informação, 34(1), 64-77.

Bendassolli, P. F., \& Soboll, L. A. P. (2011). Introdução às clínicas do trabalho: Aportes teóricos, pressupostos e aplicações. In P. F. Bendassolli, \& L. A. P. Soboll (Orgs.), Clínica do trabalho: Novas perspectivas para compreensão do trabalho na atualidade. São Paulo: Atlas.

Borges-Andrade, J. E., \& Pagotto, C. P. (2010). O estado da arte da pesquisa brasileira em psicologia do trabalho e organizacional. Psicologia: Teoria e Pesquisa, 26(esp.), 37-50.

Codo, W., Soratto, L., \& Vasques-Menezes, I. (2004). Saúde mental e trabalho. In J. C. Zanelli, J. E. Borges-Andrade, \& A. V. B. Bastos, Psicologia, organizações e trabalho no Brasil (pp.276-299). Porto Alegre: Artmed.

Coordenação de Aperfeiçoamento de Pessoal de Nível Superior/Ministério da Educação e Cultura do Brasil (CAPES/MEC). (2015). Portal de Periódicos. (Link)

Coordenação de Aperfeiçoamento de Pessoal de Nível Superior (CAPES). (2015). Avaliação. (Link)

Coordenação de Aperfeiçoamento de Pessoal de Nível Superior (CAPES). (2016). Plataforma Sucupira, (Link) 
Dejours, C. (1992). A loucura do trabalho: Estudo da psicopatologia do trabalho (5a. ed. Ampliada). São Paulo: Cortez-Oboré.

Dejours, C. (2009). Entre o desespero e a esperança: Como reencantar o trabalho? Revista Cult, 12(139), 49-53.

Dejours, C. (2013). A carga psíquica do trabalho. In M. I. S. Betiol (Org.), Psicodinâmica do trabalho: Contribuição da escola dejouriana à análise da relação prazer, sofrimento e trabalho. São Paulo: Editora Atlas.

Dejours, C. (2015a). Travail: Usure mentale. Nouvelle édition augmentée. Paris: Bayard Éditions.

Dejours, C. (2015b). Le choix: Souffrir au travail n'est pas une fatalité. Paris: Bayard Éditions.

Dejours, C., \& Abdoucheli, E. (2013). Itinerário teórico em psicopatologia do trabalho. In M. I. S. Betiol (Org.), Psicodinâmica do trabalho: Contribuição da escola dejouriana à análise da relação prazer, sofrimento e trabalho. São Paulo: Editora Atlas.

Dejours, C., \& Deranty, J.-P. (2010). The centrality of work. Critical Horizons: A Journal of Philosophy \& Social Theory, 11(2), 167-180.

Dejours, C., Dessors, D., \& Desriaux, F. (1993). Por um trabalho, fator de equilíbrio. Revista de Administração de Empresas, 33(3), 98-104.

Duarte, F. S., \& Mendes, A. M. (2013). Notas sobre o percurso teórico da psicodinâmica do trabalho. In L. G. Freitas (Org.), Prazer e sofrimento no trabalho docente: Pesquisas brasileiras. Curitiba: Juruá.

Freitas, L. G. (Org.) (2013). Prazer e sofrimento no trabalho docente: Pesquisas brasileiras. Curitiba: Juruá.

Gil, A.C. (2011). Métodos e técnicas de pesquisa social. São Paulo: Atlas.

Gondim, S. M. G., \& Bastos, A. V. B.(2009). Psicólogos organizacionais e do trabalho. Trabalho apresentado no $6^{\circ}$ Congresso Norte-Nordeste de Psicologia, Belém.

Gondim, S. M. G., \& Bastos, A. V. B.(2010). O trabalho do psicólogo no Brasil. Porto Alegre: Artmed.

Hutz, C. S., Rocha, M. L., Spink, M. J. P., \& Menandro, P. R. M. (2010). Perfil, avaliação e metas de produção intelectual dos Programas de Pós-Graduação em Psicologia. Psicologia: Reflexão e Crítica, 23(Supl. 1), 25-34.

Lancman, S. (2011). O mundo do trabalho e a psicodinâmica do trabalho. In S. Lancman, \& L. I. Sznelwar (Orgs.), Christophe Dejours: Da psicopatologia à psicodinâmica do trabalho. Brasília: Paralelo 15 / Rio de Janeiro: Editora Fiocruz.

Lancman, S., Barros, J. O., Manna, V., \& Azevedo, M. J. (2015). Saúde mental e trabalho: Apontamentos teóricos e relato de experiência em equipe multiprofissional. In K. B. Macêdo (Org.), O Diálogo que transforma: A clínica psicodinâmica do trabalho (pp. 135 - 153). Goiânia: Ed. da PUC Goiás.

Lancman, S., \& Jardim, T. A. (2004). O impacto da organização do trabalho na saúde mental: Um estudo em psicodinâmica do trabalho. Revista de Terapia Ocupacional, USP, 15(2), 82-89.

Lo Bianco, A. C., Almeida, S. S., Koller, S. H., \& Paiva, V. (2010). A internacionalização dos programas de pós-graduação em psicologia: Perfil e metas de qualificação. Psicologia: Reflexão e Crítica, 23(supl. 1), 1-10.

Macêdo, K. B. (Org.). (2015). O diálogo que transforma: A clínica psicodinâmica do trabalho. Goiânia: Editora da PUC-GO.

Martins, S. R., Bottega, C. G., Vasconcelos, A. C. L., Soboll, L. A. P., Moraes, T. D., Horst, A. C., Facas, E., \& Merlo, A. R. C. (2013). Construindo identidade: Narrativas históricas da psicodinâmica do trabalho no cenário brasileiro. In Á. R. C. Merlo, A. M. Mendes, \& R. D. de Moraes (Orgs.), O sujeito no trabalho: Entre a saúde e a patologia. Curitiba: Juruá. 
Mendes, A. M. (1999). Valores e vivências de prazer-sofrimento no contexto organizacional. Tese de doutorado, Universidade de Brasília, Brasília, DF.

Mendes, A. M., \& Araújo, L. K. R. (2012). Clínica psicodinâmica do trabalho: O sujeito em ação. Curitiba: Juruá.

Mendes, A. M., Merlo, A. R. C., Morrone, C. F., \& Facas, E. P. (2012). Psicodinâmica e clínica do trabalho: Temas, interfaces e casos brasileiros. Curitiba: Juruá.

Molinier, P. (2003). Sujeito e subjetividade: Questões metodológicas em psicodinâmica do trabalho. Revista Terapia Ocupacional Universidade de São Paulo, 14(1), 43-47.

Monteiro, J. K., Vieira, F. O., \& Mendes, A. M. (Orgs.) (2015). Trabalho \& prazer: Teoria, pesquisas e práticas. Curitiba: Juruá.

Oleto, A. F., Melo, M. C. O. L., \& Lopes, A. L. M. (2013). Análise bibliométrica da produção sobre prazer-sofrimento no trabalho nos Encontros da Associação Nacional de Pós-Graduação em Administração (2000-2010). Psicologia: Ciência e Profissão, Brasília, 33(1), 60-73.

Rossoni, L. (2006). A dinâmica de relações no campo da pesquisa em organizações e estratégia no Brasil: Uma análise institucional. Dissertação de Mestrado, Centro de Pesquisa e Pós-Graduação em Administração Mestrado em Administração, Universidade Federal do Paraná, Curitiba, PR.

Tague-Sutcliffe, J. (1992). An introduction to informetrics. Information Processing andManagement, Elmsford, 28(1), 1-3.

Tonetto, A. M., Amazarray, M. R., Koller, S. H., \& Gomes, W. B. (2008). Psicologia organizacional e do trabalho no Brasil: Desenvolvimento científico contemporâneo. Psicologia \& Sociedade, 20(2), 165-173.

Vanz, S. A. S. (2009). As redes de colaboração no Brasil (2004-2006). Tese de Doutorado, Programa de Pós-Graduação em Comunicação e Informação, Universidade Federal do Rio Grande do Sul, Porto Alegre, RS.

Vieira, F. O., Mendes, A. M., \& Merlo, Á. R. C. (Orgs.) (2013). Dicionário crítico de gestão e psicodinâmica do trabalho. Curitiba: Juruá.

World Health Organization (WHO). (2008).Health impact of psychosocial hazards at work: An overview. Geneva: WHO Press. (Link)

\section{Endereço para correspondência}

Lúcio de Souza Machado

End.: Avenida Universitária, $n^{\circ}$ 1440, Setor Universitário, Goiânia (Goiás) / CEP 74.810-210.

E-mail: 1ucio@florestaauditores.com.br

Kátia Barbosa Macêdo

End.: Avenida Universitária, no 1440, Setor Universitário, Goiânia (Goiás) / CEP 74.810-210.

E-mail: katiabarbosamacedo@gmail.com 